\title{
Collaborating With Police in the Emergency Department While Maintaining Patient Confidentiality: How Can We Improve?
}

\author{
Brodie Nolan, MD*; Alun Ackery, MD, $\mathrm{MSc}^{\dagger}$
}

\section{INTRODUCTION}

Police are commonly encountered in the emergency department (ED). They support EMS, transport patients, are a source of collateral information for health care professionals, and help provide a safe environment for hospital staff. However, there is a potential for conflict due to the nature of police investigation and the emergency physician's duty to protect patients' confidentiality and personal health information.

Although individual privacy legislature varies slightly by province, personal health information can be loosely defined as any identifying information about an individual that relates to their physical or mental health. ${ }^{1-9}$ Personal health information includes, but is not limited to, an individual's name, age, medical record number, address, telephone number, and general medical status. ${ }^{1}$ Any disclosure of patient information to police without consent could potentially violate the patient's right to privacy of personal health information. Unfortunately, it is not uncommonly the case that patients in the ED for whom the police have an interest are unable or unwilling to provide consent. In such circumstances patient health information can only be legally given to police through an exception to consent, such as if the police obtain a search warrant, court order, or subpoena.

Education for emergency medicine (EM) residents on police-physician exchanges is variable; it is mostly comprised of direct observation of how various staff physicians interact in such scenarios. It is important for EM residents to understand the legislation surrounding these practices to ensure patients' rights are protected and avoid any potential for litigation.

We conducted an extensive review of the current literature and legislation surrounding two common interactions between emergency physicians and police: the trauma patient and the emotionally disturbed patient. In our experience, these scenarios represent challenging interactions that highlight the dichotomy between the perspective of the police and emergency physicians. Following each of the case vignettes below, we outline how perceptions differ during these scenarios and offer suggestions on how the resulting interactions can be improved.

\section{THE TRAUMA PATIENT}

A 23-year-old man is brought to the ED after being stabbed in the chest and left flank. Both EMS and police are present as he is brought into the resuscitation room.

\section{The problem}

Trauma patients who are brought in by police can be extremely difficult to manage. They may be agitated due to the circumstances surrounding their injuries, drug or alcohol use, or as a result of a head injury. It is critical for ED staff to obtain an accurate history of events as well as any substance use that may explain the clinical picture; however, obtaining this information can be impeded by police presence. Patients may not be

From the *Department of Medicine, University of Toronto, Toronto, ON, Canada; and TSt. Michael's Hospital, Department of Emergency Medicine, Toronto, ON, Canada.

Correspondence to: Dr. Alun Ackery, St. Michael's Hospital, 30 Bond St. 1-008 Shuter Wing, Toronto, ON, M5B1W8; Email: alun.ackery@mail. utoronto.ca 
forthcoming for fear of criminal prosecution and may perceive the medical team as an extension of the law. Furthermore, police who are present during the resuscitation may find themselves privy to information that is expressed by the patient without knowledge of the police presence.

\section{The police perspective}

Early access to information is essential for police to efficiently perform their duties. The nature of any subsequent investigation is frequently determined by the extent of the patient's injuries. Life-threatening injuries are usually treated as a possible homicide and can result in a different approach to forensics, evidence gathering, and investigative resources. Information on the severity of injuries can also alert police about other parties who may be in imminent danger.

A key component of a police investigation is establishing chain of custody. This requires that every transfer of evidence (e.g., clothing, weapons) from person to person or place to place be documented, thus proving that nobody had access to the evidence or tampered with it and avoiding any potential for a future mistrial. As a result, if police are present in the resuscitation room and can witness clothing being put in a "belongings bag" that is then given to them, they are able to document the chain of custody very easily. If police are not allowed in the resuscitation room, and cannot witness the transfer of evidence, the courts will require someone from the health care team to vouch for its collection.

\section{The physician perspective}

The immediate priority is to assess and manage the patient, which includes obtaining an accurate history. This may require physicians to assure the patient that they are not police, and that nothing will be shared with police unless required by law. Herein lies a potential for conflict: physicians are privy to information that could assist a police investigation; however, they are bound by their duty to maintain patient confidentiality.

\section{What the law says}

Provincial privacy legislature varies slightly by location and is summarized in Table 1. Across all provinces, physicians must disclose all required patient information when presented with a search warrant, court order, or subpoena (note that the latter only requires a physician to disclose patient information when in court). In general, in the absence of patient consent, some specified patient information may be shared with police if it relates to an ongoing investigation as outlined under the Criminal Code of Canada and is necessary to facilitate an investigation. ${ }^{1-9}$ In such a case, the minimal information possible can be released (specifically: patient name, next of kin, and medical status described as stable, fair, or critical).

There are exceptions to what has been described above, such as when there is an imminent risk of serious bodily harm or death to an identifiable person or group. ${ }^{10}$ Reporting of gunshot wounds is mandatory in Ontario, British Columbia, Alberta, Manitoba, Saskatchewan,

\begin{tabular}{|c|c|}
\hline Province & Details of Legislation \\
\hline British Columbia & Disclosure permissible but not mandatory for facilitating police investigation as outlined under Criminal Code \\
\hline Alberta & $\begin{array}{l}\text { Disclosure permissible for facilitating police investigation as outlined under Criminal Code unless patient directly } \\
\text { expresses no information to be shared }\end{array}$ \\
\hline Saskatchewan & Disclosure permissible but not mandatory for facilitating police investigation as outlined under Criminal Code \\
\hline Manitoba & $\begin{array}{l}\text { Disclosure permissible for facilitating police investigation as outlined under Criminal Code unless patient directly } \\
\text { expresses no information to be shared }\end{array}$ \\
\hline Ontario & Disclosure permissible but not mandatory for facilitating police investigation as outlined under Criminal Code \\
\hline Quebec & Disclosure permissible but not mandatory for facilitating police investigation as outlined under Criminal Code \\
\hline New Brunswick & Disclosure permissible but not mandatory for facilitating police investigation as outlined under Criminal Code \\
\hline Nova Scotia & Disclosure permissible but not mandatory for facilitating police investigation as outlined under Criminal Code \\
\hline Prince Edward Island & Current legislation is being drafted \\
\hline $\begin{array}{l}\text { Newfoundland and } \\
\text { Labrador }\end{array}$ & Disclosure permissible but not mandatory for facilitating police investigation as outlined under Criminal Code \\
\hline
\end{tabular}


Quebec, and Nova Scotia. ${ }^{11-17}$ Furthermore, in British Columbia, Alberta, Manitoba, and Saskatchewan, mandatory reporting also exists for non-self-inflicted stab wounds. Reporting of such injuries is often deemed the responsibility of a hospital administrator and not the emergency physician. The reporting requirements by province in such cases is outlined in Table 2 .

Police may overhear information about a patient or view parts of the chart (e.g., a blood alcohol level) simply through being present in the ED. Any information obtained this way by police, in the absence of a search warrant or court order, cannot be acted on or used in court. ${ }^{18}$

\section{How can we improve}

An attempt to obtain consent from a patient should be made before disclosure of any information to police;

\begin{tabular}{|c|c|c|}
\hline Province & Gunshot wounds & Stab wounds \\
\hline British Columbia & Yes & Yes \\
\hline Alberta & Yes & Yes \\
\hline Saskatchewan & Yes & Yes \\
\hline Manitoba & Yes & Yes \\
\hline Ontario & Yes & No \\
\hline Quebec & Yes & No \\
\hline New Brunswick & No & No \\
\hline Nova Scotia & Yes & No \\
\hline Prince Edward Island & No & No \\
\hline Newfoundland and Labrador & No & No \\
\hline \multicolumn{3}{|c|}{$\begin{array}{l}\text { The following information is to be given to police (as per the CMPA): } \\
\text { - The fact that a patient is being treated or has been treated for a gunshot (or } \\
\text { stab) wound } \\
\text { - The patient's name, if known } \\
\text { - The name and location of the hospital or facility }\end{array}$} \\
\hline
\end{tabular}

however, if consent is not possible, it is permissible for emergency physicians to aid police by disclosing limited patient information that will help facilitate their investigation. This information should be limited to the patient's name, next of kin, and medical status, described as stable, fair, or critical. If police request further information, a polite reminder regarding patient confidentiality should suffice. However, if faced with uncooperative or demanding officers, any resulting conflicts should be quickly referred to the appropriate level of hospital administration.

Police may be asked to leave the room while a history is being taken to protect patients' confidentiality. Requests by police to stay within view of a patient can be accommodated by having officers step outside of the room if there is a glass barrier, or wait in an area far enough removed to allow patient observation while remaining outside of earshot.

\section{EMOTIONALLY DISTURBED PERSON}

A 29-year-old man was reported to be yelling aggressively at pedestrians and walking through traffic. He was combative and agitated on scene and is brought into the ED accompanied by two police officers.

\section{The problem}

Police are often the first to arrive on scene for individuals experiencing a mental health crisis who are subsequently apprehended and brought to the ED for assessment. The nature of a busy ED means that some patients accompanied by police may wait for many hours before they can be assessed by a physician, and before police officers are released to return to the community. Some EDs lack

Table 3. Ontario HSJCC strategies for implementing effective police-ED protocols for mental health patients

- Building strong relationships between police services and hospitals

- Providing cross-sectoral training for police services and hospital staff about mental health apprehension situations

- Calling ahead to the ED when a police officer is on route with a person experiencing a mental health crisis

- Establishing clear lines of communication upon arrival at the ED

- Utilizing a mental health screener form to communicate information about the circumstances and observations about the person in crisis

- Arranging a quiet room for police-accompanied visitors to the ED

- Having adequate staff support to manage mental health crisis situations in the ED

- Designating a liaison in the ED to work directly with police officers when they arrive with a person in crisis

- Establishing a written agreement between police detachments and hospitals that sets out procedures and expectations and respects patient rights

- Conducting routine monitoring and evaluation of the protocol in place, and making changes as necessary

- Ensuring person-centered care 


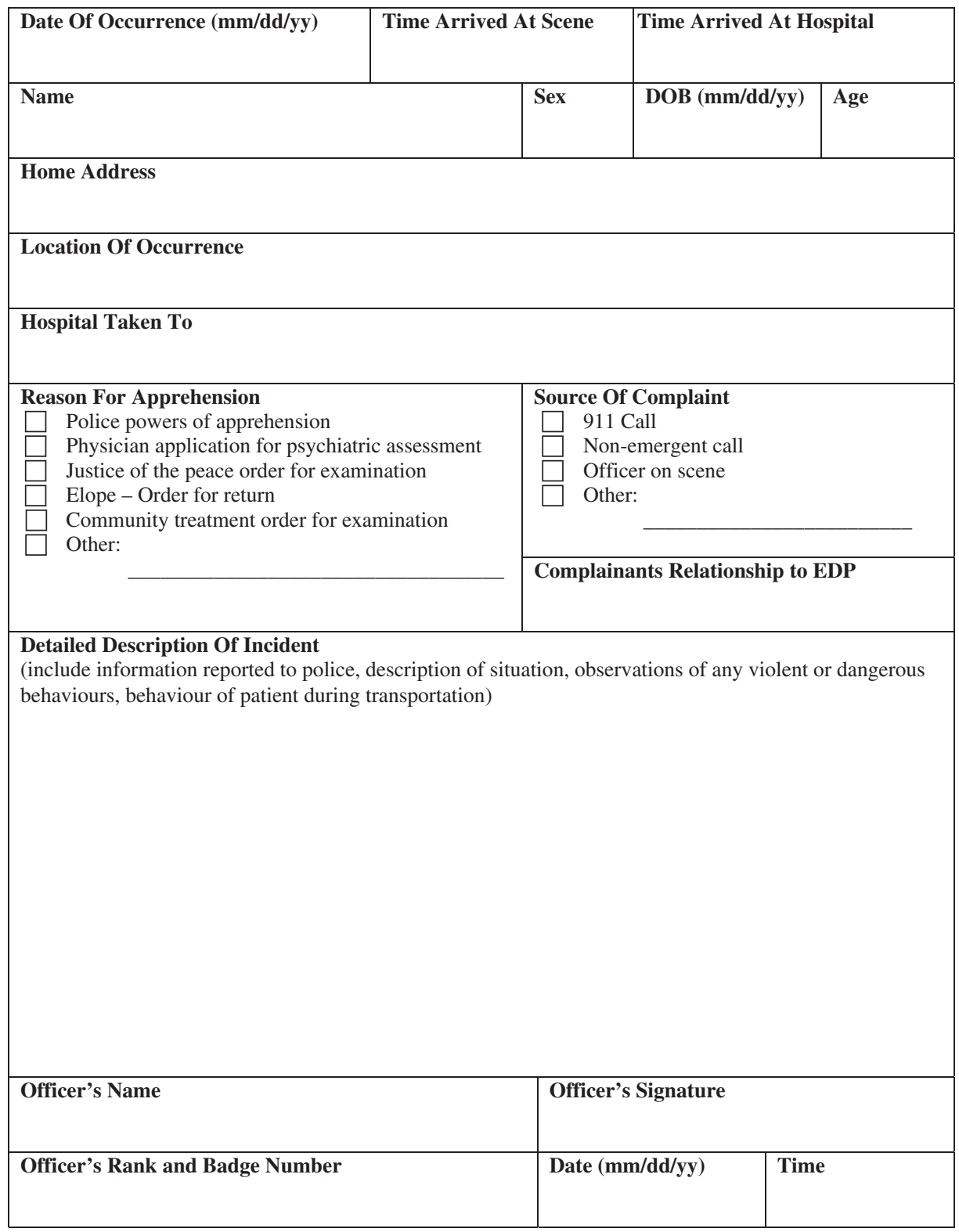

Figure 1. Emotionally Disturbed Person Information Form Example (adapted from multiple hospitals across Toronto in conjunction with Toronto Police Services)

the security or mental health personnel to deal with such scenarios, causing police to have extended stays with these patients until they are admitted to an in-patient psychiatric ward. Complicating this further is the fact that patients may be reluctant to disclose pertinent health information, such as recent drug use, when police are present.

\section{The police perspective}

Police can provide important information, such as the state of the patient on scene, which can be helpful in assessing whether or not criteria exist for an involuntary admission, and gathering information necessarily for the required Form (Emotionally Disturbed Person Information Form). Some patients brought into hospital may be in police custody for a committed crime. Ultimately, reducing waiting time for police in the ED is important for their expeditious return to community work.

\section{The physician perspective}

ED overcrowding continues to be a challenge, often leading to pressure to manage multiple acutely ill 
patients simultaneously. Appropriate assessment of psychiatric patients can take time, especially if an involuntary admission is pursued. Although some hospitals have access to crisis intervention services, these are not available at all hospitals, nor are they typically available around the clock.

\section{What the law says}

Each provincial Mental Health Act allows police to detain and escort patients to hospital if they believe they may be suffering from a mental illness. No information can be given to police without the patient's consent, apart from scenarios involving the previously stated exceptions, such as an imminent risk of serious bodily harm or death to an identifiable person or group.

\section{How we can improve}

The Human Services and Justice Coordinating Committee (HSJCC) of Ontario, in conjunction with multiple regional health authorities and local police services, has developed strategies for implementing effective police-ED protocols (Table 3). ${ }^{19}$ These strategies have applicability in other provinces, and may serve as templates for similar initiatives elsewhere, as their focus is to improve communication and streamline the process for patients with a mental health crisis who are brought in by police.

Some hospitals have developed an emotionally disturbed person information form, an example of which is provided in Figure 1. These forms are filled out by police based on their observations and information given to them about the patient prior to or during transport to hospital. The form illustrated was developed with input from both local police services and frontline hospital staff, and such resources can be an excellent tool for documenting the mental status of a patient if an involuntary admission is pursued. Such forms can also serve as a tool of handover in situations when police leave the ED before a physician has assessed the patient, or in centres where police do not routinely leave a copy of their report for the physician.

\section{CONCLUSIONS}

Issues of patient confidentiality with police presence in the ED represent a challenging aspect of emergency medical practice. A review of current provincial legislation indicates that in the absence of a search warrant or a court order, only limited patient information may be disclosed to police without patient consent. Strategies aimed at improving communication between police and ED staff may improve the process for mental health patients who are brought to hospital by police. Emergency physicians must continue to foster a positive working relationship with police, while continuing their primary duty to maintain patient confidentiality.

Conflicts of interest: None declared.

Keywords: patient confidentiality, emergency department, police

\section{REFERENCES}

1. Bill 31, Personal Health Information Protection Act, 1st Sess., 38th Leg., Ontario, 2004. Available at: www.e-laws. gov.on.ca/html/statutes/english/elaws_statutes_04p03_e.htm (accessed January 9, 2014).

2. Bill 3, Freedom of Information and Protection of Privacy Amendment Act, 4th Sess., 39th Leg., British Columbia, 2011. Available at: http://www.bclaws.ca/Recon/document/ ID/freeside/96165_00 (accessed March 19, 2014).

3. Bill 40, Health Information Act, 3rd Sess., 24th Leg., Alberta, 1999. Available at: https://www.assembly.ab.ca/ HIAReview/Health_Information_Act.pdf (accessed March 19, 2014).

4. Bill 32, Personal Health Information Act, 2nd Sess., 39th Leg., Manitoba, 2008. Available at: https://web2.gov.mb.ca/ bills/39-2/pdf/b032.pdf (accessed March 19, 2014).

5. Bill 29, Health Information Protection Act, 4th Sess., 23rd Leg., Saskatchewan, 1999. Available at: http://www.qp. gov.sk.ca/documents/english/Statutes/Statutes/H0-021.pdf (accessed March 19, 2014).

6. Bill 68, An Act Respecting the Protection of Personal Information in the Private Sector, 1st Sess., 17th Leg., Quebec, 1993. Available at: http://www2.publicationsduquebec.gouv.qc. $\mathrm{ca} /$ dynamicSearch/telecharge.php?type $=2 \&$ file $=/ P \_39 \_1 / \mathrm{P} 39$ 1_A.html (accessed March 19, 2014).

7. Bill 88, Personal Health Information Privacy and Access Act, 3rd Sess., 56th Leg., New Brunswick, 2009. Available at: http://www.gnb.ca/legis/bill/pdf/56/3/Bill-88.pdf (accessed March 19, 2014).

8. Bill 7, Personal Health Information Act, 1st Sess., 56th Leg., Newfoundland, 2008. Available at: http://www.assembly.nl. ca/business/bills/Bill0807.htm (accessed March 19, 2014).

9. Bill 76, Personal Health Information Act, 4th Sess., 61st Leg., Nova Scotia, 2012. Available at: http://nslegislature.ca/legc/ bills/61st_4th/1st_read/b076.htm (accessed March 19, 2014).

10. Smith vs. Jones, Supreme Court of Canada. 1999. Available at: http://scc-csc.lexum.com/decisia-scc-csc/scc-csc/scc-csc/ en/item/1689/index.do (accessed January 9, 2014).

11. Bill 110, Mandatory Gunshot Wounds Reporting Act, 1st Sess., 38th Leg., Ontario, 2005. Available at: http://www. e-laws.gov.on.ca/html/source/statutes/english/2005/elaws_ src_s05009_e.htm (accessed January 9, 2014). 
12. Bill 12, Gunshot and Stab Wound Disclosure Act, 2nd Sess., 39th Leg., British Columbia, 2010. Available at: http://www. bclaws.ca/EPLibraries/bclaws_new/document/ID/freeside/ 00_10007_01 (accessed January 9, 2014).

13. Bill 46, Gunshot and Stab Wound Mandatory Disclosure Act, 2nd Sess., 27th Leg., Alberta, 2009. Available: http://www.qp. alberta.ca/documents/Acts/g12.pdf (accessed January 9, 2014).

14. Bill 20, The Gunshot and Stab Wounds Mandatory Reporting Act, 2nd Sess., 39th Leg., Manitoba, 2008. Available at: http://web2.gov.mb.ca/laws/statutes/2008/c02108e. php (accessed January 9, 2014).

15. Bill 20, The Gunshot and Stab Wounds Mandatory Reporting Act, 3rd Sess., 25th Leg., Saskatchewan, 2007. Available at: http://www.qp.gov.sk.ca/documents/English/ Statutes/Statutes/G9-1.pdf (accessed January 9, 2014).

16. Bill 10, Gunshot Wounds Mandatory Reporting Act, 2nd Sess., 60th Leg., Nova Scotia, 2008. Available at: http:// nslegislature.ca/legc/statutes/gunshot.htm (accessed January 9, 2014).

17. Reporting of Gunshot and Stab Wounds. 2009. Canadian Medical Protective Association. Available at: https:// oplfrpd5.cmpa-acpm.ca/duties-and-responsibilities/-/asset_ publisher/bFaUiyQG069N/content/reporting-of-gunshotand-stab-wounds (accessed January 9, 2014).

18. Purssell R, Mahli L, Solomon R, et al. Emerg departments: Considered a safe haven from prosecution for impaired drivers involved in fatal or personal injury crashes? $B C \mathrm{Med}$ 7 2010;52(9):477-9.

19. Strategies for Implementing Effective Police-Emergency Department Protocols in Ontario. 2013. Human Services and Justice Coordinating Committee of Ontario. Available at: http://www.hsjcc.on.ca/Uploads/HSJCCPolice-ER-InfoGuide-FINAL.pdf (accessed November 12, 2013) 